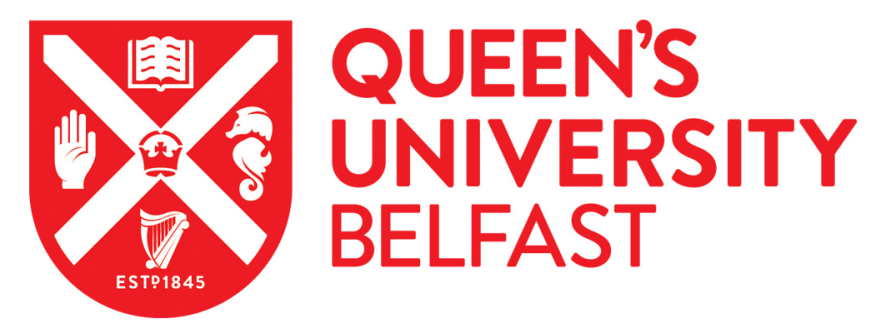

\title{
Empowering the Shamed Self: Recognition and Critical Social Work
}

Houston, S. (2016). Empowering the Shamed Self: Recognition and Critical Social Work. Journal of Social Work, 16(1), 3-21. https://doi.org/10.1177/1468017314566789

Published in:

Journal of Social Work

Document Version:

Peer reviewed version

Queen's University Belfast - Research Portal:

Link to publication record in Queen's University Belfast Research Portal

Publisher rights

This is the accepted version of an article published in the Journal of Social Work at doi: 10.1177/1468017314566789

\section{General rights}

Copyright for the publications made accessible via the Queen's University Belfast Research Portal is retained by the author(s) and / or other copyright owners and it is a condition of accessing these publications that users recognise and abide by the legal requirements associated with these rights.

Take down policy

The Research Portal is Queen's institutional repository that provides access to Queen's research output. Every effort has been made to ensure that content in the Research Portal does not infringe any person's rights, or applicable UK laws. If you discover content in the Research Portal that you believe breaches copyright or violates any law, please contact openaccess@qub.ac.uk. 


\section{Empowering the 'Shamed' Self: Recognition and Critical Social Work}

\section{Summary:}

This article provides a review of the contribution of Axel Honneth's model of recognition for critical social work. While Honneth's tripartite conceptualisation of optimal identityformation is positively appraised, his analysis of the link between misrecognition, the experience of shame and eventual sense of moral outrage, is contested. Drawing on a range of sources, including the sociology of shame, Honneth's ideas about the emotional antecedents of emancipatory action are revised to guide critical social work with misrecognised service users.

\section{Findings:}

The intellectual background to Honneth's recognition model, emanating from leading German philosophers, is described and its application to social work set out. Even so, Honneth's model is found to be deficient in one primary regard: its assumption about the emotional antecedents to quests for withheld recognition is misapprehended. In particular, the argument in this article is that the ubiquitous emotion of shame, which Honneth argues flows from misrecognition, must be carefully addressed through the medium of relationship, otherwise it might lead to repressed shame and frustrated attempts at social struggle. To this end, a social work process is delineated for dealing with shame, following episodes of misrecognition.

\section{Applications:}

Honneth's model of recognition, along with revised ideas about how to recognise and manage shame, is incorporated into a conceptual framework for critical social work practice. With this renewed understanding of the impact of shame, following misrecognition, social workers should be better equipped conceptually to enable service users to take action for empowerment.

Key words: critical social work, recognition, shame, empowerment, rights, theory, social justice 


\section{Introduction}

This article critically appraises Axel Honneth's theory of recognition (1996) and its implications for social work practice. Honneth's ideas have radically challenged notions of social justice, empowerment and human well-being within contemporary social, political and moral theory. As an influential heir to his mentors in the Frankfurt School, he continues to develop a corpus of thought concentrating on the subject's struggle to attain a wholesome identity; that is, a way of being attuned with oneself so that self-respect, selfconfidence and self-esteem flourish. The subject's experience of positive recognition from others is the axial hub around which these three aspects of self-relation turn. Moreover, Honneth sees recognition as the fundamental, overarching moral category guiding theorybuilding and politicised praxis aimed at securing social justice.

The social work profession and academy should, therefore, attempt to make sense of Honneth's substantial intellectual achievement, test its relevance and helpfulness for practice, and add critical insights to make it more pertinent to the needs of service users. This inquiry is urgent because social work must theorise the interconnection between the 'personal' and the 'political' in order to explain events in social life (Lens, 2001; Andersen, 2013; Gray \& Webb, 2013). Theory has to be conceptually sufficient so it can offer an understanding of 'private ills' (for example, forms of psychological suffering) and their link with 'public issues' (for example, discrimination, injustice, and relations of asymmetrical power). The bifuraction between the psychological and political realms of social work practice in western States has remained contentious and insufficiently explored, particularly in the neo-liberal age of globalisation, xenophobia, near imminent environmental catastrophe and the melt-down of turbo-capitalist markets (Ferguson, 2013). Simply put, the notion of recognition needs to move beyond a much popularised and vaunted term in the social science lexicon, to a psycho-social construct enabling service users to take action for empowerment. This denotes a process of change whereby sub-altern groups move from being passive spectators to engaged activists in order to enhance control of their lives and social situations (Mullaly, 2007).

In this context, social work is a unique profession because it intervenes in the interstices between personal lives, civic status (and its subordination) and the social world. 'Thus, it is 
concerned with the social and personal; the psychological and the public, the individual and (original emphasis) the collective; with the self and agencies affecting it' (Croft and Beresford, 2008, p. 400). Social workers not only advocate for service users with senior managers within their organisations (in order to canvass resources) but also respond to psychological loss, crisis and change in specialist settings such as palliative care and, more generally, transitions throughout the human lifecycle. Critical theory helps to make these interventions psychologically, culturally and politically sensitive. For example, social workers need to understand the rampant politicisation of migrants and refugees as it has a significant bearing on issues of misrecognition, inclusion, participation and integration in society. It is not enough to practice traditional casework with these groupings: increasingly social work needs to respond at the level of policy advocacy, research and public education. In all of this, social work faces a conflict between its core values (such as respect) and the political ideologies underpinning western, neo-liberal States. Recognition theory provides a lens for social workers and service users to examine these conflicts and determine 'what is going on', 'what is to be done', and 'how is it to be done'. Such is the politics of social work recognition.

As to the structure of the article, I summarise, firstly, Honneth's work on the theme of recognition and describe its resuscitation of a cardinal permise in Hegelian philosophy: the intersubjective nature of selfhood. Next, consideration is given to the social work academy's growing interest in the recognition paradigm, noting some positive appraisal but also clear-sighted critique. With these foundations in place, I highlight a central gap in Honneth's model. This refers to his assumption that experiences of disrespect, engendering the emotion of shame, lead ipso facto to social struggle aimed at seeking withheld recognition. It is argued that a reworked understanding of the psychology of shame in Honneth's work is necessary if service users are to make any recognizable headway in connecting their assaulted identities with attempts to take collective action in the outside world. In other words, the translation of experiences of disrespect (and its correlate of shame) to group empowerment, user involvement and self-advocacy, is one that can be hampered by unconscious defence mechanisms leading to repressed shame. 
Critical social work has a vital role to play here in addressing how emancipatory action might be curtailed by this psychological reaction. For example, The Disability Rights movement in the UK has not only re-defined our understanding of what types of services should be provided but also who should provide them (Coulshed, 2006). Independent living, personcentred planning, co-production, personalisation and direct payments are innovations in the UK that flow from a progressive, social model of disability. This movement has rightly highlighted that service users, themselves, can be service providers. Yet, in the process of empowering service users to take on such a role, past experiences of psychological shame, stigma, humiliation and misrecognition may need to be worked through as they can lead to psychological and social withdrawal. In effect, they are often barriers to change. It is not purely an outward matter of advocating, commissioning, and negotiating: social workers need to tune-in and demonstrate accurate empathy for psychological experiences of disrespect. This takes us to Honneth's central propositions about identity-formation and social change.

\section{Honneth's Model of Recognition}

One striking feature of Honneth's output is its self-consciously and painstakingly reflective vigilance in testing and reworking its philosophical claims. In his magnum opus, The Struggle for Recognition (1996), Honneth brought together, succinctly and coherently, a range of inter-related ideas forged out of extensive inquiries into the nature of human development in the context of unfolding historical social relations. Capturing philosophical themes, intuitions and musings, as part of an earlier fifteen year inquiry, this culminating text remained true to the leitmotif of the Frankfurt School: to maintain a strong unity between theory and praxis. A golden thread of inquiry underpinned this work knitting together the thoughts of a number of intellectual luminaries including Hegel, Feuerbach, Fichte, Mead and Habermas. The ideas emanating from this genealogy are traced briefly before outlining the centre-piece of Honneth's thinking: his tripartite model of identity-formation.

Honneth, at a preliminary stage in his thinking, was greatly inspired by Georg Hegel's early Jena writings (1979). Hegel was the first major philosopher to evince an inter-subjectivist paradigm and link it with social norms. He believed human identity flourished in the context of social relationships characterised by exchange and reciprocity. In doing so, he 
emphasised the sociality of the human subject. Even prior to the distinction between one person and another, there existed, according to Hegel, a primordial bond, or social symbiosis, between them. Hence, inter-subjectivity was viewed as an a priori phenomenon. Here, we came across the idea of a fundamental unity between people, one that even preceded their understanding of themselves as separate beings. Moreover, human engagement reached an ethical apex when subjects recognised, not only their interconnectedness, but their joint value. This view of the primacy of social life was in marked contrast to reductionist conceptions of society as an aggregate of individuals caught in a Hobessian 'war-of-all-against-all' or a Machiavellian quest for narcissistic, self-preservation.

Honneth's intellectual journey was further animated by the work of Ludwig Feuerbach (1986). For this German philosopher, the subject was a sensuous being endowed with corporeality - or a physical presence, which interacted with other embodied subjects in the social sphere. The use of the word sensuality referred to the subject's feelings, sentiments, and visceral intuitions. Upon entering the social world, the subject opened out to it and hence engaged in some form of rich inter-change with others. We were not rational automatons, argued Feuerbach, but rather beings of the heart as well as the mind. When the wordly winds of gain and loss, fame and fortune, pleasure and pain, and praise and blame blowed unpredictably through a person's life, they were inevitably met with an emotional response. In particular, the subject experienced hurt, shame and outrage when humiliated. From hurt came an instinctive impulse to act to restore a tainted identity. As such, human praxis was, for Feuerbach, a kind of emancipatory sensualism following assaults on our identity. The oppressed, thrust forward by emotional outrage and condemnation of their treatment, became political actors seeking recompense through a moral grammar of social struggle.

Feuerbach rooted these conceptions in an anthropocentric paradigm of philosophical anthropology. It suggested we developed a reflective identity through social interaction to become moral beings. Furthermore, the social aspect of our being was so ineluctably anchored in our needs that, to disregard this dimension of human life, was to show disrespect. The subject's needs for positive acknowledgement were an omnipresent reality across cultures and historical epochs, forming a moral substratum of experience. When 
need was threatened through acts of misrecognition, a space was created for a normative critique of those breaches of inter-subjectivity.

Honneth was also influenced by Johann Fichte (2000). The latter posited that selfconsciousness was formed out of a circular, reciprocal reaction with another's consciousness. This notion mirrored closely the central premise underpinning symbolic interactionism, a sociological theory developed by the American pragmatist thinker, George Herbert Mead (1967). Borrowing from Fichte and Mead, Honneth refined and developed his theory of recognition according to the premise that 'I can produce in myself the reaction that my actions are likely to evoke in the person with whom I am talking'. Thus, both philosophers articulated something essential about social life and moral behaviour: our ability to perspective-take with others in order to influence their actions and maintain a social bond. We developed a capacity as a species to carry out an internal dialogue enabling us to reflect on what others, and society at large, expected of us. So, for Honneth, formative processes in the recognition of the other involved role-taking and internal conversations about expectations of behaviour.

Yet, Honneth was clear that role-taking was not just a process of internal, monological dialogue with oneself; more than that, it involved communication with significant people. Jürgen Habermas (1986) emphasised this facet of social life when he established the conditions for egalitarian communication: a situation where speakers listened to each other and attempted to understand what was being said in order to reach a consensus. He termed this communicative action and contrasted it with a conversation where speakers were strategic in intent, using power to manipulate the discourse in accordance with predetermined ends. Honneth underscored the significance of communication but argued, contra Habermas, it was not the crucial engine driving emancipation. Coming from a postlinguistic stance, he saw the impetus for change in terms of claims for rightful identity in the widest sense possible.

Synthesising these grounding insights from various German philosophers, Honneth articulated the quintessential dimensions of recognition in social life. Formatively, they fell under three headings, namely recognition of the subject's: (a) need for love and care (b) 
rights as a human being and (c) strengths or contribution to a community. Table 1 (below) sets out these dimensions of recognition, their sources and psycho-social connotation.

\section{PLACE TABLE ONE HERE}

Self-confidence was developed in the infant by primary caretakers showing acts of love and care. Honneth looked to Winnicott's object-relations theory (1971) to substantiate this form of recognition. Winnicott suggested that the very young infant experienced a symbiotic union with her mother accompanied by an undifferentiated sense of self. Through 'good enough' mothering, or maternal recognition, this profound dependence gradually lessened as the infant became more aware of her nascent identity. Any separation anxiety would be contained psychologically by the available and sensitive mother, enabling the child to develop ontological trust, leave the 'secure base' of protected care, and explore the social world. The movement from complete dependence following birth, to relative interdependence as a mature, functioning adult, challenged Freud's view that human development was primarily a product of intra-psychic processes forged on repressed, libidinal needs. The child's inner working model, embracing the perception of self and others, could be threatened, however, by acts of child abuse leading to impaired selfconfidence in later life.

Self-respect, by way of contrast, occurred as a result of a different type of recognition, one lying in society's attribution of diverse human rights to each and every citizen. The individual was entitled to freedom of expression, the right to vote, to take part in an assembly, to own property - all indicative of the great liberal tradition of rights. But more than that, respecting the other meant she should not have to endure the privations of material inequities and impecunious hardship nor suffer xenophobic discrimination against her cultural identity. To achieve a sense of full self-realisation, subjects should also be accorded rights as full participants in the democratic polis. They should be empowered to take an active role in deliberating on policy, law and statue rather than being thrust into the role of passive recipients of centralised decrees. To return to Mead and symbolic interactionism, if role-taking was a deeply ingrained anthropological fact, an irrepressible human need, it must surely have a normative content pivoting on a consideration of the other's person's rights in the situation. To ground this point, the trinity of 'rights, respect and role-taking' 
reverberates strongly with social work approaches to young offenders. Yet, in some social systems regulating this area, a justice paradigm has prevailed over a welfare one. In the former, risk-analysis occludes needs-assessment and punishment overturns restorative care (Carr, 2012). When this occurs, role-taking is attenuated as insufficient consideration is given to the fact that many young offenders come from impoverished backgrounds. However, under the United Nations Convention on the Rights of the Child (1989), the best interests of children should be a primary consideration dominating all actions.

Self-esteem, according to Honneth, came by recognising a person possessed unique strengths or talents. People were situated in different social networks and communities where they could contribute to the well-being of others. In previous times social standing had been tied to the group to which one belonged. In the modern age, it was linked to an individual's achievement. Regardless of the period, having this contribution recognised by social networks built pride and competence. Strengths could be vocational in nature, or reflect prowess in sports, or educational attainment, or musical flair. To be competent in at least one area, and to have this recognised, enhanced resilience. It accentuated one's ability to deal with stress. Educational achievement could activate positive chain reactions or at least divert negatives ones. We know about the value of recognising skills in young people in the education system as a way of enhancing their capacity to 'bounce back' from adversity (Ungar, 2004). Self-efficacy was associated with this resilience. In contrast, misrecognition of one's contribution to the community undermined esteem and, with it, dignity. This linkage between resilience and community is taken up by Ungar's (2012) path-breaking international research. For him, building resilience is an ecologically complex and multidimensional process. Moreover, it is a process that draws on resources in both the individual and the environment. This assertion complements Honneth's stress on the domain of social networks. Ungar's findings also connect with recognition theory when he reports that services must be delivered in a respectful way, paying attention to the young person's rights, providing care, and prioritising the person over bureaucracy.

\section{Recognition and Social Work}

Honneth's work has received limited attention by the social work academy. That said, two authors have formatively evaluated its contribution to social work. They are Paul Michael 
Garrett (2010) and Stephen Webb (2010). Both eschewed the tripartite model though the latter was somewhat more positive in his overall view. Garrett pointed to the model's supposed 'psychologisation' of human problems and reductionist focus on micro encounters. Both referred to its conceptual limitations when it came to the question of the redistribution of wealth. Their concerns reflected Nancy Fraser's (Fraser \& Honneth, 2003) enduring polemic against Honneth. Fraser argued Honneth's three spheres of recognition explained cultural injustice but not exploitation in the sphere of political economy. Cleavages in class, inequalities in living standards, and material disadvantage, were undertheorised, it was claimed. For Fraser, the redress to neoliberalism lay not just in the restoration of wounded cultural identities but also in the reinstatement of the subject's status in social and economic life and her parity with others to participate equally in social situations. Fraser's argument carried some weight given the reality of oppressive class systems under neo-liberalism and the need to give redistribution a firmer footing in economic policy.

However, this critique did not give sufficient credence to Honneth's later work (2012) where the recognition concept was extended more visibly to political and economic institutions, their exploitation of the worker, and the social impact of working conditions. In making these shifts towards an understanding of political-economy, Honneth defined a leftistHegelian critique of liberalism. With this understanding, he extrapolated the third sphere of recognition to a subject's contribution within the field of labour. A person's experience of the labour market, to quote Honneth, 'must remain categorically embedded in moral experiences to such a degree that its role in obtaining social recognition does not disappear from view' (2007, p. 75). Child rearing, social care within institutions supporting vulnerable people, and so called 'housework', were all examples of realms of labour disrespected by modern society. The carer's rank in these areas was considerably devalued. The impact of unemployment, on mental health and family well-being, must also be viewed as a form of societal disrespect. For example, a long-term, loyal, hard-working employee is suddenly made redundant as a result of a competitive take-over of the firm for which he works. His subsequent depression at losing a valued role has manifest implications for his family. His children suffer, not only due to the loss of income, but also because of the psychological loss 
of their father. Thus, the capricious nature of the market weaves its way into the private sphere of family life, impacting on child welfare and ostensibly igniting a negative chain reaction in personal psycho-biographies.

Other social work commentators, including this author (Houston, 2013), have been more approving of recognition theory. Thus, Froggett (2004) drew on research conducted in a cross-professional community and healthy living centre. The practice of inter-personal recognition, she found, fostered creative forms of expression (such as the use of art and drama) and personal development. The recognition principle was seen as fundamental to developing creativity within staff and service users. By gaining confidence through creative expression, users were empowered to think about instances of misrecognition in wider domains of their lives. In a different vein, Marthinsen and Skjefstad (2011) gave credence to the recognition construct in their empirical research of a social work programme in Norway. The social workers were able to develop the service users' self-confidence by actively recognising their strengths. One important consequence of this stance was the development of occupational skills in the long-term unemployed. Cortis (2007), correspondingly, discovered Honneth's recognition-theoretic resonated strongly with the suffering described by parents in a case study exploring family support services. Commenting on Honneth's tripartite model of love, rights and strengths, she said: 'These categories give voice to the social suffering of users in the study, and meaningfully capture the outcomes they experienced by using family services' (p. 257).

Jull (2009) took up a different theme by presenting the norm of recognition in social work as a foil to institutional practices underpinned by negative judgements of service users. For Jull, judgement leads to disrespectful practice. This idea that institutions present barriers to recognition was also mirrored in Filsinger's (2003) attempt to apply Honneth's three forms of practical self-relation to psychosocial practice with people with a learning disability. Institutional regimes, it was argued, can present sources of misrecognition as witnessed in 'indignities, disregard and restrictions to autonomy' (p. 21).

We can build on these sources to link Honneth's three limbs of recognition with related approaches to social work practice (see Table 2). 


\section{PLACE TABLE 2 HERE}

Recognition as love/care centrally finds a home in relationship-based social work (Turney, 2012). The development and maintenance of a therapeutic alliance with the service user, where care is shown, sustains and nurtures relationship - even in contexts where the need for control is also present. Caring, relational social work stands in marked contrast to the cold, rational feel of some bureaucratic, welfare interventions. Indeed, Ferguson and Woodward (2009) argued relationship-based practice was a modern antidote to bureaucracy and managerialism. Computerised systems, audit checklists, actuarial, riskaverse schedules, sometimes displace the person, not recognising identity needs. Our selfimage depends on how other people react to us, what they reflect back through their facial expression, vocal tone and demeanour. For Honneth, consciousness cannot be separated from social context. It follows, therefore, that social work can be conceptualised as a form of symbolic interaction. A social worker has a major responsibility to cultivate positive thoughts of self-relation in service users by focusing on the quality of the social interaction within professional encounters. Positive interaction is the process by which the capacity to think about self is both developed and expressed. In this medium, a social worker can counter the effects of stigma and labelling. Commensurate with this focus on the symbolic world of the service user, is the requirement to understand how relationship affects intrapsychic development. To reiterate, Honneth drew on Winnicott's ideas concerning the importance of object-relations for the developing self. Attachment theory (Golding, 2008) embraces this perspective with its focus on how the 'inner working model' develops, defence mechanisms operate and attachment patterns unfold throughout the lifecourse.

Recognition, in the form of identifying strengths within others, is mirrored in strengthsbased social work where the onus is to empower service users. This approach builds on the premise people have the innate capacity to reflect, grow, adapt to their circumstances, assimiliate new information and utilise inner resources to address challenges in life. It is antithetical to a deficit-led model which negates self-esteem. Moreover, for Honneth, this form of recognition demands a social medium: a group or network which values the subject and the contribution she makes to the collective sphere. Community social work and ecological perspectives adhere to this fundamental principle (in different ways). In doing so, 
they take account of how contrasting social systems - micro, meso and macro - nurture an individual's strengths and their potential. As I have reported elsewhere (Houston \& Dolan, 2008), the assessment of social support is intrinsic here and might include the provision of a mentor to enhance a person's skills. Providing support to another person is the sine qua non of recognition.

Acknowledging and respecting the other's rights, is reflected in rights-based social work practice (Ife, 2012). The discourse on human rights occupies one of the most emotive and contested positions in contemporary socio-political debates. It lies at the epicentre of social work and its codes of practice, particularly at a time when the misrecognition of sociocultural identities is to the fore in many countries, and structural cleavages between rich and poor families are becoming increasingly apparent. Given the reality of these challenges, Honneth's recognition framework takes on a particular purchase, because it moves beyond a conception of rights as abstract entitlements to one concerned with an enhancement of personal identity. Re-formulated in this way, the law, through the medium of respectful relations, has the power to create emotional well-being. Hence, the person is not a virtual actor but rather a sensuous being dependent on daily acts of respect. Human rights must be connected with real-life, embodied people who feel pain. These ontological premises sharpen empathy for service users making it more percipient.

Rights-based social work can also be aligned, under a broad canvass, with other radical forms of practice such as critical social work (Allan et al, 2009), structural social work (Mullaly, 2007) and political social work (Webb \& Gray, 2014). These approaches share a common commitment to redress social inequality and relationships based on asymmetrical power. Whether of a modernist hue (where material conditions are to the fore), or postmodernist complexion (focusing on the celebration of difference and diveristy), the aim is to foster social change through transformative practice. Honneth's model of social justice provides a new angle on critical social work through the philosophical anthropology of the person presented earlier. Stated in another way, it is not always clear what ontological assumptions of the person underpin the various forms of critical social work and antioppressive practice. It is not always apparent what view is taken on identity-formation and the nature of social interaction. The pathologies of capitalist society must be understood in 
terms of their effects on the person, first and foremost, how they dismantle a person's being-in-the-world and psychological constitution. For Honneth, the prime mover in neoliberal de-humanization is not instrumental rationality (as stated by the early Frankfurt School theorists) nor distorted communication (as argued by Habermas). Modern social theory, the well-spring of contemporary, critical social work, must relocate its analysis in the structural conditions of reciprocal recognition. In this context, Honneth is suggesting that the intersubjective nature of human identity can act as the fillip to critical practice. Recognition, in this formulation, becomes the normative foundation for a new critical theory of the person and society.

In reviewing the above categories, it is important to state that, in practice, the different forms of recognition are interlacing. That is, love and care underpin a rights-based approach and a strengths-orientation. When practicing community social work, we are implicitly acknowledging rights of citizenship. An empowering social work response will, most likely, show all three forms of recognition. In the domain of mental health, for example, social workers are required to show care when addressing severe mental distress; reduce social isolation through creating supporting social networks; and uphold rights when advocating for users caught in the labyrinth of the psychiatric system. In mental health social work, empowerment may also take the form of supporting the development of service user, consumer and survivor perspectives. The following quote from Honneth should enliven these perspectives: 'because engaging in political struggle publicly demonstrates the ability that was hurtfully disrespected, this participation restores a bit of the individual's lost selfrespect' (1996, p. 164).

\section{Critical Social Work, Disrespect and Shame}

At this stage we need to enlarge the analysis by challenging a core premise in Honneth's theorization of social change: that is, that moral experiences of disrespect should be viewed, unproblematically, as the driving engine for demands for recognition. Contra Honneth, disrespect may often create emotional blockages to change, inertia or activate the flight mechanism. To avail of Honneth's path-breaking contribution, critical social work must rework his ideas on this theme by appraising how subjects react emotionally to experiences of disrespect. 
According to Honneth (1996), disrespect can be shown in a number of ways. First, the body can be violated as in acts of physical abuse, sexual abuse and torture. These acts represent the most fundamental forms of degradation because they result in severe humiliation and shame. It is not only the physical pain that is felt but also 'the feeling of being defensively at the mercy of another subject, to the point of feeling that one has been depived of reality' ( $p$. 132). There is lasting damage to one's confidence and trust in others. In all of this, the subject has lost autonomous control of her body and, furthermore, experiences a kind of psychological death. A second form of disrespect, argues Honneth, comes from the denial of a person's inviolable rights. As a consequence, one's personal autonomy is affected; one also loses the status of a fully-fledged citizen endowed with moral entitlements to take part in social interaction. This situation results in a loss of face and moral self-respect, with its accompanying shame, because the subject is no longer recognised as capable of forming moral judgements. For Honneth, the experience can represent a 'social death'. Finally, according to Honneth, the third face of disrespect reveals itself when one's contribution to the community is not acknowledged. This omission impacts negatively on status, self-worth and self-esteem. When one's abilities are not recognised by the social group to which one is affiliated, it leads to a sense of social ostracism - a lack of connection with networks that are meant to validate one's place in the established, social order. Using metaphorical terms, Honneth argues that cultural denigration leads to psychic scars and injuries.

To reiterate, these three forms of disrespect, for Honneth, lead to humiliation, denigration and shame, endangering human identity much like the way a pernicious infection threatens bodily health. However, unlike Hegel and Mead, who failed to address the societal implications of disrespect, Honneth saw shame as the prime mover in motivating a subject to engage in social struggle or conflict. He therefore seized upon this missing link connecting psychological suffering to pragmatic action. Feeling ashamed propelled one into a quest for the denied social recognition that sustained human identity. In his inimitable style, Honneth put the point as follows: 'in the context of the emotional responses associated with shame, the experience of being disrespected can become the motivational impetus for a struggle for recognition. For it is only by regaining the possibility of active conduct that individuals 
can dispel the state of emotional tension into which they are forced as a result of humiliation' (p. 138).

At this juncture, what are we to make of Honneth's thoughts concerning the moral and psychological antecedents of social struggle? While the tripartite model of identity formation has much relevance to social work, as argued above, his assertion that shame unproblematically generates political struggle is naïve and must surely confound antioppressive practice rather than enrich it. Phenomenological, sociological and psychoanalytical evidence (considered below) presents a different set of findings regarding the psycho-social dynamics of shame. Attempts to translate shame into user-empowerment may well flounder unless this is understood.

Shame, as an emotion in human life, has received increasing attention in a range of literature - both fictional and academic. From a psychoanalytical perspective, Helen Lewis (1971) discovered shame was ubiquitous when analysing numerous verbatim transcripts of psychotherapeutic sessions with her clients. In fact, the experience of shame was much more prevalent than other emotional reactions. Like Honneth, Lewis saw shame as quintessentially a reaction to a disrupted social bond - when one became disconnected from both understanding and being understood by another. However, it was often suppressed or by-passed. Quite assuredly, it did not lead neatly to Honneth's emancipatory praxis.

The emotion of shame has also received notable coverage from a sociological perspective. Georg Simmel (1904) examined how people needed to express themselves creatively but feared the consequences of departing from social conventions. To do so, would be to invoke shame. Alternatively, for Charles Cooley (1922), shame was a by-product of self-reflection: wondering what the other was thinking about one's actions. Being conscious of how we appeared to others, through a 'looking-glass mirror', could either lead to shame or pride depending on whether one felt judged or validated. Thus, these emotions were the outcome of a self-monitoring process in the form of an inner dialogue linked to social interaction. Cooley's thoughts in this regard influenced Irving Goffman's (2005) idea that face saving overtures (in order to 'cut a good figure'), and deferential demeanour, were integral to the interaction order. In effect, they were designed to fend off rejection and 
embarrasment. A person experiencing the latter emotion was strongly motivated to reestablish the social bond, to be relieved from the crippling impact of shame. This was a somewhat different conclusion to the one drawn by Honneth.

The sociologist, Norbert Elias, made a novel contribution to this area. In his land-mark exploration of the civilizing process through pre-modern and modern times (2000), he linked the experience of shame with departures from 'manners' in social life. Simply put, a civilized person must abide by socially approved etiquette. Children had been socialised into this rubric from an early age and with it came ever decreasing shame thresholds, making shame more ubiquitous. Yet, for Elias, as with Lewis, shame was often a hidden experience, one not easily identified nor vented. It could not be viewed automatically as an inexorable source of politicised contestation.

The sociologist, Thomas Scheff (2000), acknowledged the salience of this body of work on shame. Like Honneth, he believed human beings were intrinsically social in nature. Indeed, he argued we were ineluctably driven to maintain the social bond with others. Preserving social connectedness necessitated, though, that we adhered to a 'deference-emotion system'. In other words, actors strived to maintain social attunement with each other by submitting to idealised, social expectations. If we failed to live up to these expectations, the emotion of shame often appeared. Shame thus acted as a social regulator of behaviour. By way of contrast, when we believed we had met what was required of us, interactively, then pride, the converse of shame, would result with its positive ramifications for the self. Notably, given their ontological prominence in social interaction, Scheff argued shame and pride could be considered the master emotions in human life, occurring throughout many cultures and exhibited through historical events and artistic traditions. They were quintessential and ubiquitous feelings. More importantly, Scheff saw shame as often unacknowledged by the subject or by-passed endorsing the observations of Lewis, Goffman and Elias. One reason for this was that shame was recursive: it reacted back on itself, so that we became shamed about feeling shame in the first place. The process could be mutually reinforcing and insuperably destructive, generating anger, as depicted in the figure below:

\section{PLACE FIGURE 1 HERE}


As can be seen, shame commences with the perception that a bond with someone has been disrupted or broken. There follows negative consequences for the 'self'. In short, selfesteem becomes tarnished. When this occurs, a person might experience shame due to a negative evaluation of self. Feeling this way often produces anger, because to be humiliated, is a painful experience. Anger, in turn, can further disrupt the social bond because it can be seen as an attack on the self. The cycle mirrors Honneth's misrecognition thesis up to the point when shame is experienced. For Scheff, shame then becomes a buried affair leading to potentially destructive cycles of anger and relational breakdown. Honneth, in marked contrast, presents it as an enlightening gateway to political action - given the right social context. However, the previously highlighted body of psychological and sociological work supporting Scheff's stance is noteworthy. It questions, therefore, Honneth's understanding of the psycho-dynamics of shame. That said, it is important to retain Honneth's important premises on recognition and identity (outlined earlier) and yet accommodate Scheff's insights. Such an undertaking might provide critical social work practice with a deeper understanding of the inter-connection between misrecognition, shame and empowerment.

To make this inter-connection more visible, I contend shame might be approached in a social work encounter as follows (see Figure 2 below):

PLACE FIGURE 2 HERE 
It is axiomatic that a caring, holding relationship, where a therapeutic alliance is struck, offers the best medium for helping someone address disturbing emotions such as shame and guilt. Indeed, this is a cardinal principle of social work (Turney, 2012) and is synonymous with what Ferguson terms 'intimate practice' (2013). It also primarily reflects Honneth's first limb of recognition - the need for love and care. Crucially, this relationship should be devoid of negative judgement. From the security of this connection, a service user might begin to explore episodes in her life when she had been misrecognised and the feelings engendered. The experience of (buried) shame may be present and identified through shame markers such as blushing, negative self-talk, the pain of feeling different to others, a leap to anger, or a deep sense of embarrassment. The antecedents to such inner distress might be considered in terms of Honneth's three forms of misrecognition: withholding care to a person, denying her rights, or failing to acknowledge her strengths. Identifying and exploring shame, bringing repressed feelings into conscious awareness, harrowing as it may be, can effect catharsis and assist in managing the emotion. Inner mindfulness of the impact of shame on one's thoughts and bodily states can lead to the technique of gently 'letting-go' of the experience instead of investing in repression or its ostensible transmutation into anger. Social workers can help at this point to reverse shame to restore pride by enacting Honneth's three limbs of identity-formation with the service-user: recognising the person's need for care and solicitude, her rights and strengths. By regaining some sense of pride, service-users are better placed to take action for empowerment - seeking the lost recognition they deserved without having to also deal with the debilitating effects of shame hampering the empowerment process.

The various components of Honneth's model of recognition, and the re-worked view on shame based on the work of Scheff and others, can be collated into a conceptual framework for social work practice (see Table 3 below).

\section{PLACE TABLE 3 HERE}

A framework such as this can be used to enable service users to explore experiences of recognition and misrecognition in their life-pathways and the presence of pride or shame. It 
also provides the social worker with an understanding of what methods, skills and approaches are appropriate to address different forms of misrecognition. When shame is identified, a shame-sensitive form of social work practice, depicted in figure 2 above, can be employed to help ameliorate it and instil pride. For service users, the latter orientation is more conducive to examining the impact of the domains of the 'personal' and the 'political' on their lives compared with the repressive effects of shame. In doing so, the framework also enables users to take action for empowerment. Here, the social worker must use her relationship with the service user to recognise the latter's worth, to show care, acknowledge rights and locate strengths. Relationship-based social work, reflecting the philosophical anthropology of Honneth and his intellectual precursors, is the medium par excellence for growth and change.

The framework also sensitizes social workers to some of the fundamental psycho-social dynamics underpinning oppression and connects this understanding with different types of anti-oppressive and rights-based interventions. In doing so, it acts as a conceptual tool enabling students to reflect when on placement; social workers to tune-in to a new referral; and social work academics to consider some of the essential elements of a value-led curriculum. Moreover, it can be used to undergird anti-oppressive supervision moving beyond a bureaucratic, risk-averse, check-list model to put the 'social' back into social work. Hence, supervisor and supervisee could consider how recognition and misrecognition have played out in the lives of service users and how the 'ethics of recognition' ought to shape case assessment, planning, decision-making, management and evaluation. The examination of care and control conflicts, and work with reluctant and resistant young people and adults, takes on a particular purchase when examined through the lens of recognition theory and the disabling effects of shame. Negative reactions from service users may well reflect a central feeling that they have been disrespected in some fundamental way. A resistant young person may have had a life-time of abuse and denigration in his family and institutional care contrary to Honneth's first limb of identity-formation. The lens of recognition gets to the heart of the matter. 


\section{Conclusion}

German philosophy contains a fecund vein of ontological insights about the human condition, the pre-requisites for personal identity and, most importantly, human flourishing. The contours of this school of thought have been traced noting Hegel's foundational proposition that our sense of self is quintessentially a 'social' affair. Honneth's development of this corpus of thought, addressing particularly our practical relation-to-self, has been discussed noting the salience for social work of the three limbs of optimal identityformation, namely recognition in terms of care, rights, and strengths. However, sociological insights about shame, as an emotional response to misrecognition, are at odds with Honneth's premise that it is the antecedent to social action; it is here that Scheff's work has been brought to bear to rework this aspect of the recognition model. With this renewed understanding of the impact of shame, social workers are better equipped conceptually to empower service users to make the link between misrecognition and acts of resistance or contestation. It is the attainment of pride in oneself which activates a belief that change to the prevailing social order is possible. Critical social work practice is quintessentially a response to human injustice and oppression that builds from a deep ontological understanding of the self, hurt, humiliation, shame and also the conditions required for optimal self-confidence, self-esteem and self-respect. Fuelled by a philosophical anthropology of the self, social workers can develop renewed insights into the fundamental nature of social 'being' realising that the ' $\mathrm{l}$ ' is in the 'We' and vice-versa (Honneth, 2013). Arguably, this philosophical insight ought to unite different forms of radical, rights-based and anti-oppressive approaches in social work.

\section{Funding}

This study did not attract any funding. 


\section{References}

Allan, J., Briskman, L. \& Pease, B. (2009). Critical social work: Theories and practices for a socially just world. New South Wales: Allen \& Unwin.

Andersen, T. (2013). Against the wind: Male victimization and the ideal of manliness. Journal of Social Work, 13(3), 231-247. Doi: 10.1177/1468017311410002.

Carr, N. (2012). Criminal and juvenile justice. In M. Gray \& S. Webb (Eds), The Sage handbook of social work (pp. 597-612). London: Sage.

Cooley, C.H. (1922). Human nature and the social order. New York: Scribner's.

Coulshed, V. (2006). Social work practice (4th Ed). Basingstoke: Palgrave Macmillan.

Cortis, N. (2007). Using community services: A case study in the politics of recognition. In J. Connolly, M. Leach, \& L. Walsh (Eds), Recognition in politics (pp.253-269). Cambridge: Cambridge Scholars Publishing.

Croft, S. \& Beresford, P. (2008). Perspectives on social work. In M. Davies (ed), The Blackwell Companion to Social Work (pp. 393-401). Oxford: Blackwell.

Elias, N. (2000). The civilizing process: Sociogenetic and psychogenetic investigations. Oxford: Blackwell.

Ferguson, H. (2013). Critical best practice. In M. Gray \& S. Webb (Eds), The new politics of social work (pp. 116-127). London: Palgrave Macmillan.

Ferguson, I. \& Woodward, R. (2009). Radical social work. Bristol: Policy Press.

Feuerbach, L. (1986). Principles of the philosophy of the future. Indianapolis: Hackett Publishing.

Fichte, J.G. (2000). Foundations of the natural right. Cambridge: Cambridge University Press.

Filsinger, D. (2003). Reflections on the concept of recognition in psychosocial practice. Psychiatrische Praxis, 30(1), 21-27. Doi:10.1055/s-2003-38548

Fraser, N. \& Honneth, A. (2003). Redistribution or recognition? London: Verso. 
Froggett, L. (2004). Holistic practice, art, creativity and the politics of recognition. Social Work and Social Sciences Review, 11(3), 29-51. Doi: 10.1921/17466105.11.29

Garrett, P.M. (2010). Recognising the limitations of the political theory of recognition: Axel Honneth, Nancy Fraser and social work. British Journal of Social Work, 40(5), 1517-1533. Doi: 10.1093/bjsw/bcp044.

Goffman, E. (2005). Interaction ritual. Pistcataway, New Jersey: Transaction Publisher.

Golding, K. (2008). Nurturing attachments. London: Jessica Kingsley.

Gray, M. \& Webb, S. (Eds) (2013). The new politics of social work. London: Palgrave Macmillan.

Habermas, J. (1986). The theory of communicative action (vol. 1). Cambridge: Cambridge University Press.

Hegel, G.W.F. (1979). The system of ethical life. Albany: University of New York Press.

Honneth, A. (1996). The struggle for recognition: The moral grammar of social conflicts. London: Polity Press.

Honneth, A. (2007). Disrespect: The normative foundations of critical theory. Oxford: Polity.

Honneth, A. (2012). The I in the we: Studies in the theory of recognition. Cambridge: Polity Press.

Houston, S. \& Dolan, P. (2008). Conceptualising child and family support: The contribution of Honneth's critical theory of recognition. Children and Society, 22(6), 458-469. Doi: 10.1111/j.1099-0860.2007.00126.x

Houston, S. (2013). Social work and the politics of recognition. In M. Gray \& S. Webb (Eds) The new politics of social work (pp. 63-76). Basingstoke: Palgrave Macmillan.

Ife, J. (2012). Human rights and social work: Towards rights-based practice (3 ${ }^{\text {rd }}$ ed.). Cambridge: Cambridge University Press. 
Jull, S. (2009). Recognition and judgement in social work. European Journal of Social Work, 12(4), 403-417. Doi: 10.1080/13691450902981418.

Lens, V. (2001). When the personal and the political collide. Journal of Social Work, 1(3), 361-363. Doi: 10.1177/146801730100100308.

Lewis, H. (1971). Shame and guilt in neurosis. New York: International Universities Press.

Marthinsen, E. \& Skjefstad, N. (2011). Recognition as a virtue in social work practice. European Journal of Social Work, 14(2), 195-212. Doi: 10.1080/13691451003744317.

Mead. G.H. (1967). Mind, self and society. Chicago, Illinois: Chicago University Press.

Mullaly, B. (2007). The new structural social work. Oxford: Oxford University Press.

Scheff, T. (2000). Shame and the social bond: A sociological theory. Sociological Theory, 18(1), 84-99. URL: http://www.jstor.org/stable/223283.

Simmel, G. (1904). Fashion. International Quarterly, X(3), 130-155.

Turney, D. (2012). A relationship-based approach to engaging involuntary clients: The contribution of recognition theory. Child and Family Social Work, 17(2), 149-159. Doi: 10.1111/j.1365-2206.2012.00830.x.

Ungar, M. (2004). Nurturing hidden resilience in youth. Toronto: University of Toronto Press.

Ungar, M. (2012). The social ecology of resilience. London: Springer.

United Nations. (1989). Convention on the rights of the child. Geneva: United Nations.

Webb, S. (2010). (Re)Assembling the left in social work: The politics of redistribution and recognition in social work. British Journal of Social Work, 40(8), 2364-2379. Doi: 10.1093/bjsw/bcq070.

Webb, S. \& Gray, M. (Eds) (2014). The new politics of social work. Basingstoke: Palgrave Macmillan.

Winnicott, D. (1971). Playing and reality. Harmondsworth: Penguin. 